\title{
"Effectiveness of Planned Teaching Program on Knowledge regarding Non pharmacological Techniques of relieving labor pain among Primigravida women."
}

\author{
Himanshu Vyas ${ }^{1}$, Aashish Parihar ${ }^{2}$, Naveen Kumar Sharma ${ }^{3}$ \\ ${ }^{I}$ Nursing Tutor, College of Nursing, All India Institute of Medical Science, Jodhpur \\ ${ }^{2}$ Nursing Tutor, College of Nursing, All India Institute of Medical Science, Jodhpur \\ ${ }^{3}$ Nursing Tutor, College of Nursing, All India Institute of Medical Science, Jodhpur
}

\begin{abstract}
A Quasi experimental study to assess the effectiveness of a planned teaching program on knowledge regarding Non pharmacological techniques of relieving labor pain in primigravida women in selected hospitals at Gulbarga, Karnataka. The sample consisting of 60 primigravida mothers was selected by using Simple random sampling technique. The tool comprised of knowledge questionnaires. The pre-test was conducted and planned teaching program was administered on the primigravida women immediately after the pretest. The post test was conducted after one week of the pre test with same questionnaires. The data obtained were analyzed using descriptive and inferential statistics. In pre-test the sampled subjects were having poor knowledge on non pharmacological techniques of managing labor pain. i.e. about 34\%. Regarding the post-test the sampled subject had an improved knowledge on non pharmacological techniques of managing labor pain i.e. about $83.9 \%$. In relation to Planned teaching program, the paired " $t$ " test showed that, the teaching program was statistically significant at $p<0.0001$ level in primigravida women. These data proved that the knowledge of primigravida women had been markedly increased after the administration of planned teaching program.

Keywords: Primigravida women, Non pharmacological techniques, Knowledge
\end{abstract}

\section{INTRODUCTION}

Labor pain is the pain and discomfort associated with the contraction of uterus during Labor. Pain levels reportedly by Laboring women vary widely. Pain levels seems to be influenced by fears and anxiety levels, experience with prior childbirth, cultural ideas of childbirth and pain, mobility during Labor and support given during Labor. The advancement in the field of medical sciences has demanded for comprehensive care in different areas. Labor pains have become a major issue of concern for expecting mothers. They are expecting to relieve the pain but at the same time reluctant to use analgesics. The management of labor pain is one of the main goals of maternity care. Most pain during childbirth results from normal physiological events. If nurses understand the nature and effects of pain during the Labor process they will be better prepared to provide supportive care. Physical comforts include a variety of non pharmacological and pharmacological interventions.

Today's man lives in a world where everything moves with a tick of a clock and moves around in a world with high technological advancement. Care and concern, of human being is replaced by high technology. Nowadays the human touch is somewhere is missing down the lane. So in this context, nurses are the only one who will render "hi-touch" care in the midst of "hi-tech" care. Nurses will care for mothers by providing relaxation and other techniques which help to promote Labor and relieve pain.

Rather than making the pain disappear the midwife and other caregiver assist the woman to cope with it, build her self confidence and maintain a sense of mastery and wellbeing. Touch and massage touching another human being can communicate positive message such as caring concern reassurance or love. Massage is the intentional and systematic manipulation of the soft tissues of the body to enhance health and healing is during Labor to enhance relaxation and reduce pain and suffering. The massage can lower pain intensity at each phase of Labor. Anxiety level also decreases in massage during the latent phase and the massage is helpful in pain relief and psychological support.

Some of the selected non pharmacological techniques which are frequently used during Labor are: Massage therapy, Breathing and Relaxation, Hydrotherapy, Acupressure and Hypnosis.

A study was conducted on evaluation of intrapartum non pharmacological pain relief methods used during Labor. This retrospective descriptive study examined which non pharmacological pain relief techniques laboring women use most often and effectiveness of the chosen techniques. Of the 10 non pharmacological 
strategies rated by the sample $(\mathrm{N}=46)$, breathing techniques, relaxation, acupuncture and massage were found to be the most effective.

Therefore the investigators were interested to continue with the study and intended to extend a helping hand to primigravida mothers.

The Problem Statement:

\section{RESEARCH ELABORATIONS}

"A Study to assess the effectiveness of planned teaching program on knowledge regarding selected non pharmacological techniques in managing Labor pain among primigravida women admitted in antenatal ward of selected hospitals at Gulbarga, Karnataka".

\section{OBJECTIVES}

1) To assess the level of knowledge regarding non pharmacological techniques to manage Labor pain among primigravida women by using structured knowledge questionnaire.

2) To develop planned teaching program on selected non pharmacological techniques of managing Labor pain among primigravida women.

3) To evaluate the effectiveness of planned teaching program on knowledge regarding selected non pharmacological techniques of managing Labor pain among Primigravida women.

\section{HYPOTHESIS :}

$\mathrm{H}^{1}$ : There will be a significant increase in the knowledge of primigravida women when they will undergo a planned teaching program.

\section{MATERIALS AND METHODS}

Population : Primigravida women.

Sample : Primigravida women in 3 selected hospitals at Gulbarga, Karnataka.

Sample size : 60 primigravida women.

Setting : 3 selected hospitals at Gulbarga, Karnataka.

Conceptual framework - The conceptual framework for this study was derived from " General system Theory. According to general system theory, a system is a set of components or unit interacting with each other within a boundary that filters the kind and the rate of flow of inputs and outputs to and from the systems.

Figure 1: Conceptual frame work based on Vonberalanaffy General System model 1968

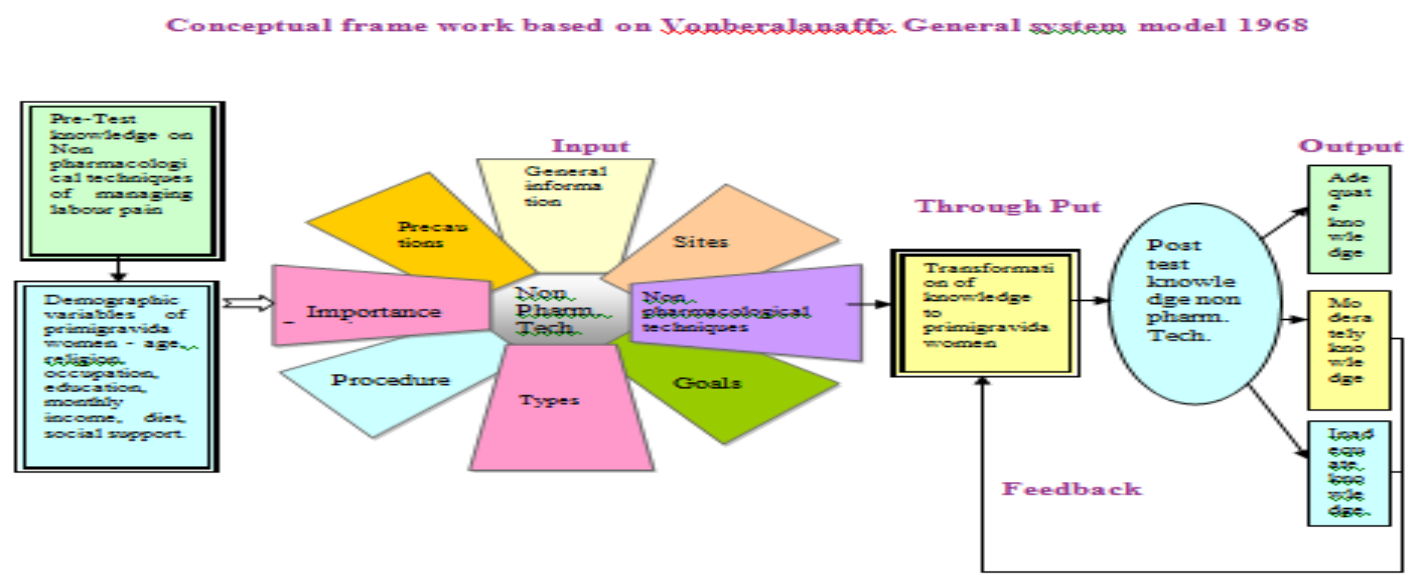




\section{RESEARCH DESIGN :}

The research design selected for the present study was quasi experimental one group pretest and post test design.

Table 1: Quasi experimental one group pretest and post test design.

\begin{tabular}{|c|l|l|}
\hline Pretest & Treatment & Post test \\
\hline Knowledge test & PTP & Knowledge test \\
\hline $\mathrm{O}_{1}$ & $\mathrm{X}$ & $\mathrm{O}_{2}$ \\
\hline
\end{tabular}

O1 $=$ Pre-test. $\quad \mathrm{X}=$ Intervention. $\quad \mathrm{O} 2=$ Post-test.

Variables under study

Independent variable (I V) = Planned teaching program

Dependent variable (DV) = Performance of pretest and post-test.

Attribute Variable (A.V) = Age, educational status, Occupation, family income, religion and Food habit, social support

\section{Description of the tool.}

The instrument used for this study is knowledge questionnaire, which was designed by the investigator. It consists of 3 parts.

Part I : Demographic variables -10 items

Part II: Knowledge questionnaire -32 items

Section A: Knowledge statements regarding Labor and Labor pain.

Section B: Knowledge statements related to non pharmacological techniques in managing Labor pain in Primigravida women.

\section{$\underline{\text { Score Interpretation: }}$}

$<50 \%$ - Inadequate knowledge.

51-75\% - Moderately adequate knowledge.

$>75 \%$ - Adequate knowledge.

Data Collection: After getting formal approval from the College Principal and the Hospital authorities the investigators went on to collect data. Structured knowledge questionnaire was used to collect data in the pretest as well as the post test. The data collection continued for around 1 month duration.

Results : The findings revealed that out of the 60 samples primigravida women were found highest in the age groups between $18-22$ age group that was $41.7 \%$ followed by $30 \%$ in the age group $22-26,16 \%$ in the age group of $26-30$ and the lowest were found in the age group of $30-34$ i.e. $11.7 \%$.

Nearly one third $(30 \%)$ of the subjects were illiterate and $70 \%$ were educated out of them $15 \%$ were primary and PUC each, $21.7 \%$ were educated up to High school level and $18.3 \%$ degree and above.

Assessment of knowledge on Non Pharmaceutical techniques

Table2: Mean, SD and mean score percent of knowledge score before PTP.

\begin{tabular}{|l|l|c|c|c|c|c|}
\hline Sino. & \multicolumn{1}{|c|}{ Knowledge } & Max possible score & Mean & SD & $\begin{array}{c}\text { Range } \\
\text { Mean score } \\
\%\end{array}$ \\
\hline 1. & Labor and Labor pains & 12 & 4.08 & 1.31 & $2-8$ & 34 \\
\hline 2. & $\begin{array}{l}\text { Non Pharmacological } \\
\text { techniques }\end{array}$ & 20 & 7.6 & 2.42 & $6-19$ & 38 \\
\hline 3. & Over all & 32 & 5.84 & 1.87 & $8-27$ & 36 \\
\hline
\end{tabular}


The table 2 shows the summary of statistical outcomes of knowledge on non pharmacological techniques of managing Labor pain in primigravida women before PTP. The knowledge score was assessed in two areas such as knowledge on non pharmacological techniques and knowledge on Labor and Labor pains with test items of $20 \& 12$ in each. So the maximum possible score for these two domains was 20 and 12 and for over all knowledge were 32. The mean knowledge on Non pharmacological techniques of managing Labor pain was 7.6 with SD 2.42 and ranging from $6-19$ before PTP. The mean score percent was computed and it was found to be 38\%. The mean score was little higher in the area of knowledge on Labor and Labor pains i.e. mean, 4.08 with SD 1.31. It was raging from 2-8 with mean score percent $34 \%$. The overall knowledge on non pharmacological techniques of managing Labor pain exercise before PTP resulted with mean 5.84, SD 1.87 out of 32. It ranged in between $8-27$ with mean score percent $36 \%$. On an average the sampled subjects were having poor knowledge on Non pharmacological techniques.

Assessment of knowledge on Non pharmacological techniques in managing Labor pain after PTP

Table 3: Mean, SD and mean score percent of knowledge score after PTP.

\begin{tabular}{|l|l|c|c|c|c|c|}
\hline SL. No. & \multicolumn{1}{|c|}{ Knowledge } & Max possible score & Mean & SD & Range & $\begin{array}{c}\text { Mean score } \\
\%\end{array}$ \\
\hline 1. & Labor and Labor Pains & 12 & 10 & 2.1 & $05-12$ & 83.3 \\
\hline 2. & Non pharmacological techniques & 20 & 16.9 & 1.9 & $15-20$ & 84.5 \\
\hline 3. & Over all & 32 & 13.5 & 2.0 & $20-32$ & 83.9 \\
\hline
\end{tabular}

The table 3 shows the summary of statistical outcomes of knowledge on Non pharmacological techniques and Labor and Labor pains after PTP. The knowledge score was assessed in two areas such as knowledge on non pharmacological techniques and knowledge on Labor and Labor pains with number of test items $20 \& 12$ in each. So the maximum possible score for these two domains was 20 and 12 and over all knowledge were 32 . The mean knowledge on Non pharmacological techniques was 16.9 with SD1.9 and ranging from 15 - 20after PTP. The mean score percent was computed and it was found to be $84.5 \%$. The mean score was little higher in the area of knowledge on Labor and Labor pains i.e. mean, 10 with SD 2.1 It was raging from 5 - 12 with mean score percent $83.3 \%$. The overall knowledge on Non pharmacological techniques and Labor and Labor pains after PTP resulted with mean 13.5, SD 2 out of 32. It ranged in between $20-32$ with mean score percent 83.9 .

On an average the sampled subject's knowledge improved after PTP.

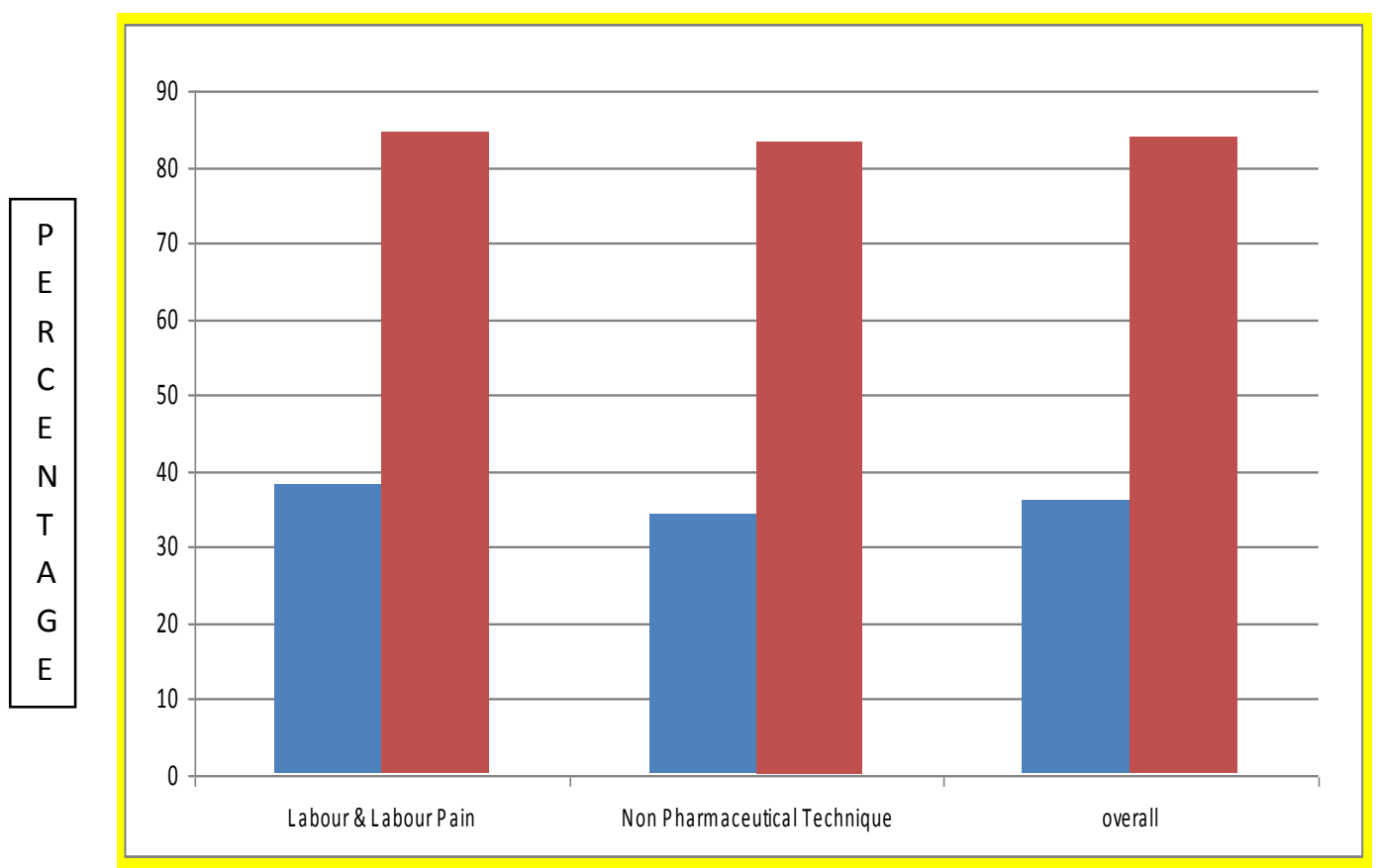

KNOWLEDGE

Figure 2: Mean Score Percent Pre \& Post Test Knowledge. 
Evaluating the effectiveness of PTP

Table 4: Paired " $\mathrm{t}$ " test analysis of pre test and post test score of knowledge on PTP.

\begin{tabular}{|c|c|c|c|c|c|c|c|c|c|}
\hline \multirow[t]{2}{*}{ S.No. } & \multirow[t]{2}{*}{ Knowledge } & \multicolumn{2}{|c|}{ Pre } & \multicolumn{2}{|c|}{ Post } & \multirow{2}{*}{$\begin{array}{c}\text { Paired mean } \\
\text { difference }\end{array}$} & \multirow[t]{2}{*}{ t-value } & \multirow[t]{2}{*}{ df } & \multirow[t]{2}{*}{ P-value } \\
\hline & & Mean & SD & Mean & SD & & & & \\
\hline 1. & $\begin{array}{l}\text { Labor and Labor } \\
\text { pains }\end{array}$ & 4.08 & 1.31 & 10 & 2.1 & 5.92 & .34 & 59 & 0.0001 \\
\hline 2. & $\begin{array}{l}\text { Non } \\
\text { pharmacological } \\
\text { techniques }\end{array}$ & 7.6 & 2.42 & 16.9 & 1.9 & 9.3 & 2.47 & 59 & 0.0001 \\
\hline 3. & Over all & 5.84 & 2.4 & 13.5 & 2.0 & 5.28 & .248 & 59 & 0.0001 \\
\hline
\end{tabular}

*significant at 0.0001 level (highly significant).

Though it was seen that the post test knowledge scores more than the pre test knowledge scores, it is essential to put under statistical significance. So, suitably the paired t-test was chosen and worked out. The results were shown in the table 3. The paired mean difference of knowledge on Non pharmacological techniques before and after PTP was 9.3 and it was statistically significant at 0.0001 level (i.e., $\mathrm{P}<0.0001$, highly significant).

Similarly for knowledge on Labor and Labor pains have got increased after PTP. The paired t-test was carried out and the results $(\mathrm{t}$-value $=0.34, \mathrm{df}=59 \& \mathrm{P}<0.0001)$ significant. The knowledge assessed through entire tool on an overall was also statistically significant at 0.0001 level ( $\mathrm{t}$-value $=.248, \mathrm{df}=59, \mathrm{P}<0.0001$ ).

There results undoubtedly confirm that the PTP proved to be significantly effective in improving the knowledge on non pharmacological techniques in managing Labor pains in the sampled subjects.

\section{CONCLUSION :}

The study was done to assess the effectiveness of Planned teaching program on the knowledge regarding Non pharmacological techniques of relieving labor pain in primigravida women. The result showed that the pretest knowledge mean score was 36\% which increased to posttest knowledge mean score of $83.6 \%$. this shows that the planned teaching program was effective and such plans should be included in the antenatal health teaching programs so that antenatal mothers can learn non pharmacological techniques of relieving Labor pain and can better adjust with the physiology of labor.

\section{REFERENCES :}

[1] Lowder Milk Perry Bobak, Text Book of Maternity Nursing Mosby $5^{\text {th }}$ edition 1999, Page No. :301-307

[2] Dutta DC. Text Book of Obstetrics, 5th edition,2001 Page Number 113-117

[3] Sherwen, Text Book of Maternity Nursing, 6th edition, 2003,Mosby Page No. 265-271

[4] Myles Text book for Midwives, Fraser Cooper, 14th Edition page no.471-480

[5] Text book for midwives, Annama Jacob Page number 161-162

[6] www.pubmed.com

[7] Nursing Nightingale Times, May 2008 issue ,Page number 15 -20 